\title{
Work related impairment of nasal function in Swedish woodwork teachers
}

\author{
Mats Åhman, Mats Holmström, Irena Cynkier, Erik Söderman
}

\begin{abstract}
Objective-To study the relation between exposure and nasal function in woodwork teachers.

Methods-39 selected woodwork teachers employed full time and 32 control subjects (other school personnel) were examined at the beginning and at the end of a working week with symptom rating, nose and throat inspection, rhinomanometry, nasal mucociliary clearance test, and a smell identification test. During one working day of the same week climate, dust and terpene concentrations were measured in all 39 schools.
\end{abstract}

Results-The ventilation rate was highest in rooms with mechanical ventilation. Range of total dust (personally sampled) was $0 \cdot 12-1 \cdot 18 \mathrm{mg} / \mathrm{m}^{3}$, respirable dust $0.02-0.21 \mathrm{mg} / \mathrm{m}^{3}$, and terpenes (area sampled) $0.02-6.8 \mathrm{mg} / \mathrm{m}^{3}$. In contrast to the control subjects, the woodwork teachers had more nasal symptoms on the Thursday afternoon than on the Monday morning, especially those working in rooms without mechanical ventilation. Their mucociliary clearance worsened during the week (mean increase $4 \mathrm{~min}$, $P<0.001)$. A small impairment of olfactory function was also found, but their rhinomanometric values did not change significantly. Nasal symptoms correlated weakly with the percentage of respirable dust in the total dust. Otherwise there were no significant dose-effect relations between measured dust or terpene concentrations and nasal tests.

Conclusions-The woodwork teachers had mainly reversible nasal complaints, impaired nasal mucociliary clearance and olfactory function related to the work environment, with dust concentrations below the Swedish threshold limit value of $2 \mathrm{mg} / \mathrm{m}^{3}$.

(Occup Environ Med 1996;53:112-117)

Keywords: wood dust; terpenes; nasal function

Nasal complaints have previously been reported in occupational groups exposed to wood dust. ${ }^{1-7}$ In the Swedish compulsory school, specialist teachers have since the 1950 s been employed to teach wood and metalwork, which is an obligatory subject for all pupils. For these teachers woodwork is predominant and metalwork is a smaller part of their teach- ing. We have recently performed a questionnaire study of 130 woodwork teachers in Stockholm because of reports of respiratory complaints. Of these woodwork teachers $55 \%$ described a work related nasal obstruction, and many of them also had other nasal complaints such as runny nose $(27 \%)$, sneezing $(39 \%)$, nose bleed (15\%), and impaired smell $(22 \%)$, the prevalence being significantly higher than in a control group of other school personnel. ${ }^{8}$

Impaired mucociliary clearance has been reported as one mechanism behind nasal complaints related to wood dust. ${ }^{49}$ Otherwise, nasal function has been sparsely investigated in workers exposed to wood dust.

To study the relation between the exposure and nasal function, we decided to examine a selected group of woodwork teachers with tests of nasal physiology and exposure measurements during a working week.

\section{Material and methods}

SUBJECTS

The exposed group was selected from the population of 130 woodwork teachers in Stockholm already described. ${ }^{8}$ The selection criteria were full time work (24 lesson hours or more per week) and employment for at least three years. In all 54 woodwork teachers fullfilled these criteria. Six of them refused to participate, one had retired as a woodwork teacher, and seven could not participate within the time scheduled (two terms). According to the previous questionnaire data, the non-participants $(n=14)$ worked in dusty rooms with inferior ventilation and less efficient cleaning methods than the others, but employment periods and the prevalence of current or previous nasal complaints did not differ significantly. One teacher examined was excluded as his records were lost. Thus, 39 woodwork teachers participated in the study.

Thirty two control subjects were selected from other school personnel (31 of them were other teachers). The control subjects were matched to the woodwork teachers for school, sex, age, height, and smoking habits. School personnel with frequent exposure to irritants or previous work as woodwork teachers were excluded. Because the matching was not complete and six woodwork teachers were without controls, the matched pairs were not kept united in the statistical analyses. One woodwork teacher got two control subjects. The frequency of a positive Phadiatop, which had been determined as an atopy marker in con- 
Table 1 Background data in the woodwork teachers $(n=39)$ and control group $(n=32)$

\begin{tabular}{lcr}
\hline & Woodwork teachers & Control group \\
\hline Age (y, m (SD)) & $44 \cdot 9(9 \cdot 4)$ & $44 \cdot 9(8 \cdot 1)$ \\
Height (cm, m (SD)) & $179 \cdot 1(8 \cdot 3)$ & $179 \cdot 4(5 \cdot 9)$ \\
Women (n (\%)) & $3(7 \cdot 7)$ & $2(6 \cdot 3)$ \\
Smokers (n (\%)) & $13(30 \cdot 0)$ & $8(25 \cdot 0)$ \\
Phadiatop positive (n (\%)) & $16(41 \cdot 0)$ & $9(28 \cdot 1)$ \\
School employment (y, m (SD)) & $17 \cdot 4(10 \cdot 3)$ & $18 \cdot 1(9 \cdot 2)$ \\
\hline
\end{tabular}

nection with a previous immunological study, ${ }^{10}$ was somewhat higher in the woodwork teachers than in the control group, but the difference was not significant (table 1). No subject had a current upper airway infection during the week studied.

The project was approved by the Ethics Committee of Huddinge University Hospital, and informed consent was obtained from each participant.

\section{EXPOSURE MEASUREMENTS}

The environments in the rooms were measured during a whole working day (generally five to six hours) on a Tuesday or a Thursday in the same week as the nasal tests. No measurements were performed in the workrooms of the control subjects. The following work environment factors were studied in the rooms:

\section{Indoor climate}

The temperature and relative air humidity were measured three to four times during the day with an Assman aspiration psychrometer. The air flow was measured in 31 rooms with a Swema Flow 230 or a Wallac air flow meter. In rooms with Flow Master displacement ventilation $(n=5)$, the projected value for the air flow was used. In three rooms, the air flow was impossible to measure, but it was considered to be almost zero. The ventilation rate was calculated from air flow and room volume.

\section{Dust exposure}

Airborne dust (total dust and respirable dust) was sampled during a whole working day with personal equipment. Area sampling of total dust was also performed with the equipment on a stand in the middle of the room $1.5 \mathrm{~m}$ above the floor. Total dust was collected on a membrane filter (Millipore, cellulose ester) mounted in a $37 \mathrm{~mm}$ cassette, and respirable dust was sampled with a size selective particle cyclone sampler (Casella). For all dust sampling, the flow through the filters was about $21 / \mathrm{min}$. Gravimetric analysis of the dust was carried out according to Swedish standards. ${ }^{11}$ While these dust measurements were going on, the short term exposure (10 minutes) to dust was repeatedly examined with a direct reading instrument (Sibata).

\section{Terpene exposure}

Area sampling of airborne terpenes ( $\alpha$-pinene, $\beta$-pinene, and $\delta$-carene and the sum of these) was performed in all rooms during a whole working day at the same place as area sampling of total dust, with charcoal tubes and a flow of about $0 \cdot 2 \mathrm{l} / \mathrm{min}$. The terpenes were then desorbed in $\mathrm{CS}_{2}$ and determined by gas chromatography (HP5880) with a packed glass column and a flame ionization detector. ${ }^{11}$

\section{NASAL TESTS}

The tests of nasal physiology were performed at Huddinge hospital on the Monday morning after two days without exposure to wood dust, and the same tests were repeated on the Thursday afternoon after work. All woodwork teachers and controls participated in the same tests as follows:

(1) A visual analogue scale (VAS) was used for symptom evaluation. The assessments were subjectively marked on $0-10$ scales which considered anterior secretion, obstruction, itching, postnasal discharge, and irritation. At examination on Thursday the subject was not allowed to see his Monday evaluation.

(2) The medical examination of the upper airways was focused on the nose (colour of the nasal mucosa, degree of swelling, anatomical deviation, secretion, crusts, and bleeding) and throat.

Rhinomanometry was carried out as described by Kumlien and Schiratzki. ${ }^{12}$ Briefly, the pressure drop and air flow rate in the nose are recorded during inhalation, and the flow pressure curve is shown on an oscilloscope. The curve is photographed and used for calculations of the angle v2 for statistical analysis and nasal breathing resistance $\mathrm{R} 2$ $\left(\mathrm{Pa} / \mathrm{cm}^{2} / \mathrm{s}\right) \quad(\mathrm{R} 2=\tan \mathrm{v} 2)$ as described by Broms. ${ }^{13}$

Sence of smell was assessed with the University of Pennsylvania smell identification test (UPSIT), marketed as The Smell Identification Test (Sensonics, Haddonfield, NJ, USA). After scratching and sniffing patches impregnated with microencapsulated odour, the test subject had to make forced choices, rendering a maximum potential score of 40 . Between 32 and 40 correct answers are regarded as within the normal range, $18-32$ as hyposmic, and $<18$ as anosmic. ${ }^{14}$

Mucociliary activity was tested with a spot of Cardiogreen sterile indocyanine green (Hynson, Westcott, and Dunning Products, Maryland, USA) placed on both inferior turbinates $1 \mathrm{~cm}$ behind the anterior border of the turbinate. The time taken for the spot to reach the rhinopharynx was measured with repeated inspections. A transport time of 20 minutes or more through both nostrils was considered to be pathological. The method has previously been used and described in other studies of woodworkers. ${ }^{45}$

\section{STATISTICS}

Fisher's exact test was used for calculation of differences in the frequency of complaints and other factors between the groups. The distribution of rated symptoms was skewed, and nonparametric tests were therefore used for comparing the rated symptoms between the groups (Mann-Whitney U test) and for evaluating the correlation between symptoms and nasal tests or exposure variables (Spearman's rank correlation coefficient $(\rho)$ or Kendall's rank correlation coefficient $(\tau))$. There was a 
Table 2 Measured dust and terpene concentrations during a working day in the workshops $(n=39)$

\begin{tabular}{|c|c|c|c|}
\hline & Mean & Range & $T L V^{5}$ \\
\hline \multicolumn{4}{|l|}{ Personal sampling: } \\
\hline Total dust $\left(\mathrm{mg} / \mathrm{m}^{3}\right)$ & 0.57 & $(0 \cdot 12-1 \cdot 18)$ & 2 \\
\hline Respirable dust (mg/m $\mathrm{m}^{3}$ ) & $0 \cdot 10$ & $(0.02-0 \cdot 21)$ & - \\
\hline Fraction (\%) respirable dust & & & \\
\hline in total dust & $20 \cdot 4$ & $(1 \cdot 6-57 \cdot 8)$ & - \\
\hline \multicolumn{4}{|l|}{ Area sampling: } \\
\hline Total dust $\left(\mathrm{mg} / \mathrm{m}^{3}\right)$ & $0 \cdot 38$ & $(0 \cdot 06-1 \cdot 24)$ & 2 \\
\hline Terpenes $\left(\mathrm{mg} / \mathrm{m}^{3}\right)$ & 0.68 & $(0.02-6.80)$ & 150 \\
\hline$\alpha$-Pinene & 0.49 & $(0 \cdot 01-5 \cdot 72)$ & 150 \\
\hline$\beta$-Pinene & 0.04 & $(0.00-0.25)$ & 150 \\
\hline$\delta$-Pinene & $0 \cdot 15$ & $(0 \cdot 01-1 \cdot 12)$ & 150 \\
\hline
\end{tabular}

normal distribution of the nasal tests and exposure measurements, and therefore parametric tests were used for analysing these parameters.

Differences in test results between the groups were evaluated with Student's $t$ test, and the correlations between tests and measured work environmental factors were evaluated from linear regression.

\section{Results}

\section{EXPOSURE}

The mean temperature was $20.5^{\circ} \mathrm{C}$ (range $17 \cdot 8-23 \cdot 3^{\circ} \mathrm{C}$ ) and the mean relative air humidity was $33.8 \%$ (range $21 \cdot 3-51 \cdot 4 \%$ ) in the rooms which are within normal ranges for indoor climate in Sweden. The mean ventilation rate was 1.9 and it was higher in rooms with mechanical ventilation $(n=22)$ than in the others (mean $3 \cdot 3$, range $1 \cdot 0-6 \cdot 0$, and mean 0.3 , range $0 \cdot 0-1 \cdot 1$, respectively, $\mathrm{P}<0.001$, unpaired $t$ test). Thirty rooms had an automatic ventilation system for dust exhaust at the machines as well as for vacuum cleaning the benches. Air cleaners were installed in $\mathbf{1 5}$ of those rooms.

The concentrations of total dust were below the Swedish threshold limit value (TLV) ${ }^{15}$ of 2 $\mathrm{mg} / \mathrm{m}^{3}$ (table 2). Rooms with good general ventilation had lower dust levels than the other rooms. Rooms lacking mechanical ventilation, air cleaner, and dust exhaust at the machines, and rooms where dry sweeping was used for cleaning had in general higher dust concentrations than the others (table 3 ). The correlation between the total dust concentration and the

Table 3 Total dust (personally sampled) and terpene concentration (area sampled) in workshops with different ventilation systems, dust exhaust equipment, and cleaning routines

\begin{tabular}{|c|c|c|}
\hline $\begin{array}{l}\text { Work environment } \\
\text { factor }\end{array}$ & $\begin{array}{l}\text { Total dust } \\
\left(\mathrm{mg} / \mathrm{m}^{3}\right) \\
\text { mean }(S D)\end{array}$ & $\begin{array}{l}\text { Terpenes } \\
\left(\mathrm{mg} / \mathrm{m}^{3}\right) \\
\text { median (range) }\end{array}$ \\
\hline \multicolumn{3}{|c|}{ Mechanical ventilation: } \\
\hline $\begin{array}{l}\text { Yes }(n=22) \\
\text { No }(n=17)\end{array}$ & $\begin{array}{l}0.58(0.24) \\
0.57(0.24)\end{array}$ & $\begin{array}{l}0.17(0.02-2.80) \\
0.41^{\star}(0.09-6.80)\end{array}$ \\
\hline \multicolumn{3}{|l|}{ Process ventilation: } \\
\hline $\begin{array}{l}\text { Yes }(\mathrm{n}=30) \\
\text { No }(\mathrm{n}=9)\end{array}$ & $\begin{array}{l}0.54(0.21) \\
0.70(0.30)\end{array}$ & $\begin{array}{l}0.28(0.02-6.80) \\
0.40(0.07-1.57)\end{array}$ \\
\hline \multicolumn{3}{|l|}{ Air cleaner: } \\
\hline $\begin{array}{l}\text { Yes }(n=15) \\
\text { No }(n=24)\end{array}$ & $\begin{array}{l}0.50(0.24) \\
0.62(0.23)\end{array}$ & $\begin{array}{l}0.28(0.02-6.80) \\
0.23(0.05-1.57)\end{array}$ \\
\hline \multicolumn{3}{|c|}{ Dust exhaust exists: } \\
\hline $\begin{array}{l}\text { Yes }(n=35) \\
\text { No }(n=4)\end{array}$ & $\begin{array}{l}0.55(0.23) \\
0.78(0.23)\end{array}$ & $\begin{array}{l}0.28(0.02-6.80) \\
0.15(0.07-0.24)\end{array}$ \\
\hline \multicolumn{3}{|c|}{ Cleaning with broom: } \\
\hline $\begin{array}{l}\text { Yes }(\mathrm{n}=22) \\
\text { No }(\mathrm{n}=17)\end{array}$ & $\begin{array}{l}0.64 \dagger(0.27) \\
0.49(0 \cdot 16)\end{array}$ & $\begin{array}{l}0.23(0.07-2.21) \\
0.28(0.02-6.80)\end{array}$ \\
\hline
\end{tabular}

$\star P<0.05$ (Mann-Whitney U test).

$+\mathrm{P}<0.05$ (unpaired $t$ test) respirable dust concentration (personally sampled) was low $(r=0 \cdot 18, \mathrm{P}>0 \cdot 10)$, but there was a positive correlation $(r=0.46, \mathrm{P}<0.01)$ between the respirable dust concentration and the percentage of respirable dust in the total dust (counted from the mass concentrations) and an inverse correlation $(r=-0.63$, $P<0.001)$ between the total dust concentration and the percentage of respirable dust in the total dust.

With a direct reading instrument (Sibata), varying and increasing dust concentrations were measured during a working day. Especially grinding with sandpaper and cleaning the benches with a broom generated high peaks while airing by opening the windows during breaks obviously lowered the dust concentration.

The measured terpene concentration in the air was low in all rooms (table 2), $\alpha$-pinene being the highest terpene. The terpene concentration was significantly lower in rooms with mechanical ventilation than in the other rooms (table 3). There was no significant correlation between measured dust and terpene concentrations.

\section{NASAL FUNCTION}

The woodwork teachers reported a higher occurrence of work related nasal complaints than the control group. The previous questionnaire study of the 39 woodwork teachers examined had also reported an impaired sense of smell. ${ }^{89}$ The medical examination showed more woodwork teachers with a septum deviation $(n=25)$ than the controls $(n=12$, $P<0.05$, Fisher's exact test). Symptom evaluation with VAS on the Monday morning did not show any significant differences between the groups, but on the Thursday the woodwork teachers had more symptoms than the controls, especially nasal obstruction and irritation (table 4).

Rhinomanometry showed no significant differences between the groups either on the Monday morning or on the Thursday afternoon (table 5). Rated symptoms of nasal obstruction by VAS did not correlate significantly with rhinomanometric values.

Nasal mucociliary clearance did not differ between the groups on the Monday morning, but on the Thursday afternoon impaired clearance was found in the woodwork teachers (table 5). Eight woodwork teachers but no control subject had a mucociliary clearance of 20 minutes or more on the Thursday ( $P<0.01$, Fisher's exact test). When all values from the woodwork teachers and controls were pooled, a significant correlation was found between mucociliary clearance and all rated symptoms, except secretion (Kendall's $\tau$ $=0.15(\mathrm{P}<0.01) v$ nasal obstruction and $\tau$ $=0.17(\mathrm{P}<0.01) v$ total VAS $)$. This correlation was unchanged after adjustment for age and smoking habits.

The UPSIT score was equal in the groups on the Monday morning. The control group had higher UPSIT scores on the Thursday than on the Monday (table 5). The UPSIT results did not change significantly among the 
Table 4 Rated symptoms (VAS 0-10) on the Monday and the Thursday in woodwork teachers $(n=39)$ and the control group $(n=32)$

\begin{tabular}{|c|c|c|c|c|}
\hline \multirow[b]{2}{*}{ Symptom } & \multicolumn{2}{|c|}{ Monday } & \multicolumn{2}{|c|}{ Thursday } \\
\hline & Mean & $\begin{array}{c}\text { Median } \\
\text { (range) }\end{array}$ & Mean & $\begin{array}{c}\text { Median } \\
\text { (range) }\end{array}$ \\
\hline \multicolumn{5}{|l|}{ Runny nose: } \\
\hline Woodwork teachers & 0.59 & $0.0(0-5)$ & 1.00 & $0.0(0-6)$ \\
\hline Controls & $0 \cdot 84$ & $0.0(0-7)$ & 0.69 & $0.0(0-7)$ \\
\hline \multicolumn{5}{|l|}{ Nasal obstruction: } \\
\hline Woodwork teachers & $2 \cdot 05$ & $1.0(0-8)$ & $2 \cdot 77^{\star} \dagger$ & $2 \cdot 0(0-8)$ \\
\hline Controls & $1 \cdot 38$ & $1.0(0-6)$ & 1.50 & $1.0(0-8)$ \\
\hline \multicolumn{5}{|l|}{ Posterior discharge: } \\
\hline Woodwork teachers & $0 \cdot 85$ & $0.0(0-6)$ & 0.77 & $0.0(0-6)$ \\
\hline \multirow{2}{*}{\multicolumn{5}{|c|}{ Itching nose: }} \\
\hline & & & & \\
\hline Woodwork teachers & 0.46 & $0.0(0-6)$ & $0.74 \ddagger$ & $0.0(0-7)$ \\
\hline Controls & $0 \cdot 22$ & $0.0(0-5)$ & 0.06 & $0.0(0-1)$ \\
\hline \multicolumn{5}{|l|}{ Nasal irritation: } \\
\hline Woodwork teachers & $1 \cdot 15$ & $0.0(0-9)$ & $2 \cdot 05^{\star} \sqrt{5}$ & $2 \cdot 0(0-7)$ \\
\hline Controls & 0.63 & $0.0(0-8)$ & 0.44 & $0.0(0-8)$ \\
\hline \multicolumn{5}{|l|}{ Total VAS: } \\
\hline Woodwork teachers & $5 \cdot 10$ & $3.0(0-21)$ & $7 \cdot 289 \pi$ & $7 \cdot 0(0-23)$ \\
\hline Controls & $3 \cdot 47$ & $2 \cdot 0(0-22)$ & $2.97^{\prime \prime}$ & $2 \cdot 0(0-18)$ \\
\hline
\end{tabular}

${ }^{\star} \mathrm{P}<0.05$ (paired $t$ test of the change from Monday to Thursday within the group)

$+P<0.05$ (Mann-Whitney $U$ test of the difference of rated symptoms between the groups on the same day).

$\ddagger P<0.01$ (Mann-Whitney $U$ test of the difference of rated symptoms between the groups on the same day).

$\oint P<0.001$ (Mann-Whitney $U$ test of the difference of rated symptoms between the groups on the same day).

$\mathbb{P}<0.01$ (paired $t$ test of the change from Monday to Thursday within the group).

woodwork teachers, but nine woodwork teachers, who had reported an impaired sense of smell, had a deteriorated UPSIT score on Thursday compared with Monday (mean -1.8 (1.9), $P<0.05$, paired $t$ test). The UPSIT score of woodwork teachers with septum deviation also deteriorated during the weak from Monday to Thursday (mean -0.8 $(1.8), P<0.05)$. With all values from the groups pooled, there was a weak negative correlation between the UPSIT score and the rated total VAS after adjustment for age and smoking habits (Kendall's $\tau=-0 \cdot 12$, $P<0.05)$ and between the UPSIT score and mucociliary clearance $(r=-0.29, \mathrm{P}<0.01)$ but not between the UPSIT score and the rhinomanometric values $(r=0 \cdot 07, \mathrm{P}>0 \cdot 10)$.

\section{EXPOSURE EFFECT RELATIONS}

The woodwork teachers working in rooms lacking mechanical ventilation had significantly more severe nasal symptoms on the Thursday afternoon than on the Monday morning, and this pattern was not so evident in teachers working in mechanically ventilated

Table 5 Rhinomanometry (Rtot), mucociliary clearance (MCC) and smell identification test (UPSIT) on the Monday and the Thursday in woodwork teachers $(n=39)$ and control group $(n=32)$

\begin{tabular}{|c|c|c|c|c|}
\hline & \multicolumn{2}{|l|}{ Monday } & \multicolumn{2}{|l|}{ Thursday } \\
\hline & Mean (SD) & (range) & Mean (SD) & (range) \\
\hline \multicolumn{5}{|l|}{ Rtot $\left(\mathrm{Pa} / \mathrm{cm}^{3}\right) / \mathrm{s}:$} \\
\hline Woodwork teachers & $2 \cdot 74(12 \cdot 8)$ & $(8-66)$ & $26 \cdot 2(10 \cdot 9)$ & $(9-51)$ \\
\hline \multicolumn{4}{|l|}{$\operatorname{MCC}(\min ):$} & \\
\hline Woodwork teachers & $12 \cdot 6(4 \cdot 2)$ & $(5-22)$ & $16 \cdot 4^{\star}+(6 \cdot 5)$ & $(5-30)$ \\
\hline Controls & $11.5(3.3)$ & $(6-16)$ & $11.3(3.9)$ & $(4-20)$ \\
\hline \multicolumn{5}{|l|}{ UPSIT (scores): } \\
\hline $\begin{array}{l}\text { Woodwork teachers } \\
\text { Controls }\end{array}$ & $\begin{array}{l}34 \cdot 6(3 \cdot 1) \\
34 \cdot 4(3 \cdot 1)\end{array}$ & $\begin{array}{l}(27-40) \\
(24-39)\end{array}$ & $\begin{array}{l}34 \cdot 2(2 \cdot 8) \\
35 \cdot 3+(2 \cdot 8)\end{array}$ & $\begin{array}{l}(27-39) \\
(28-39)\end{array}$ \\
\hline
\end{tabular}

$\star \mathrm{P}<0.001$ (paired $t$ test of the change from Monday to Thursday within the group).

$+\mathrm{P}<0.001$ (unpaired $t$ test of the difference of rated symptoms between the groups on the same

$+\mathrm{P}<0 \cdot 0$
day).

$\pm \mathrm{P}<0.05$ (paired $t$ test of the change from Monday to Thursday within the group)

$\oint \mathrm{P}<0.05$ (unpaired $t$ test of the difference of rated symptoms between the groups on the same day).
Table 6 The change ( $=$ difference) in rated symptoms (VAS 0-10) and nasal function tests from Monday to Thursday in woodwork teachers working in rooms with and without mechanical ventilation

\begin{tabular}{|c|c|c|}
\hline \multirow[b]{2}{*}{ Symptom or test } & \multicolumn{2}{|c|}{ Mechanical ventilation } \\
\hline & $\begin{array}{l}\text { No } \\
(n=17) \\
\text { Mean }(S D)\end{array}$ & $\begin{array}{l}\text { Yes } \\
(n=22) \\
\text { Mean }(S D)\end{array}$ \\
\hline $\begin{array}{l}\text { Runny nose } \\
\text { Nasal obstruction } \\
\text { Posterior discharge } \\
\text { Itching nose } \\
\text { Nasal irritation } \\
\text { Total VAS } \\
\text { Rtot } \\
\text { Mucociliary clearance } \\
\text { UPSIT score }\end{array}$ & $\begin{array}{l}+0.7(1 \cdot 4) \\
+0.7(1 \cdot 7) \\
-0.2(1 \cdot 2) \\
+0.6^{\star}(0.9) \\
+1 \cdot 3+(1 \cdot 5) \\
+3 \cdot 1 \ddagger(2 \cdot 6) \\
-1 \cdot 7(14 \cdot 7) \\
+3.9 \ddagger(3.8) \\
-0.4(2 \cdot 3)\end{array}$ & $\begin{array}{l}+0.2(1.3) \\
+0.7(2.3) \\
0.0(1.5) \\
+0.1(1.0) \\
+0.6(2.5) \\
+1.5(6.3) \\
-0.8(10.7) \\
+3.6+(5.0) \\
-0.3(1.6)\end{array}$ \\
\hline
\end{tabular}

$\star \mathrm{P}<0.05 ;+\mathrm{P}<0.01 ; \neq \mathrm{P}<0.001$ (paired $t$ test).

Rtot $=$ rhinomanometry.

rooms (table 6). There were significant but rather weak correlations between the percentage of respirable dust in the total dust and the change from Monday to Thursday in nasal obstruction (Spearman's $\rho=-0.32, \mathrm{P}<$ $0.05)$, runny nose $(\rho=+0.45, P<0.01)$, and itching nose $(\rho=+0.41, P<0.01)$. Otherwise, there was no significant correlation between symptoms and test results and measured levels of total or respirable dust and terpenes.

\section{Discussion}

EXPOSURE

The activities in the rooms varied greatly during the term. At the beginning of the term pupils planned their tasks, midterm they used the machines, and towards the end sanding and finishing were predominant. For this reason, our measurements must be regarded as a typical cross section of exposure for the whole group of woodwork teachers during the study period; but they were probably not especially typical for the particular room at another time.

Probably the dust level also varied from day to day. The dust level is influenced by type and degree of dust producing activity, sawing, sanding, turning, drilling, and other woodwork. It is also related to number of pupils, elimination factors - for example, dust exhaust at the dust sources (machines and manual woodwork at the benches), air cleaners, general ventilation, frequency of airing, cleaning methods, and cleaning discipline. The dust concentrations measured must therefore be regarded as a balanced sum of the influences from different work environment factors.

The percentage of respirable dust in the total dust also depends on the type of wood and woodwork. In general, sanding operations generate a higher fraction of small particles than for example turning and sawing. ${ }^{16}$ In this study the percentage of respirable dust in the total dust showed great variations $(2-58 \%)$. This fraction correlated positively with the measured respirable dust concentration and inversely with the measured total dust concentration, a pattern which has been reported previously. ${ }^{17}$

The concentration of terpenes was very low in all rooms, and the exposure to terpenes is therefore probably negligible. 
NASAL FUNCTION

Compared with the control group, the woodwork teachers had more nasal complaints and rated more symptoms (especially blocked nose) at the end than at the beginning of a working week, a pattern suggesting aetiological factors in the work environment.

In the woodwork teachers, the rhinomanometric values did not change significantly during the working week, nor did they correlate significantly with nasal symptoms (including nasal obstruction). Such a poor correlation has been reported elsewhere. ${ }^{18}$ The Thursday test was performed about one hour after the last lesson and it cannot be excluded that the short time away from exposure during the trip to the hospital may have been sufficient for possible nasal obstructive changesfor example, vasodilation-to improve. As the rhinomanometric values show some variance, it is also possible that two test occasions are insufficient to detect significant changes in this rather small study group. The sensation of obstruction may also be a result of swollen mucosa in the ethmoidal area where the wood dust is known to be trapped, ${ }^{19}$ and such local swelling is scarcely detected with the rhinomanometric technique. ${ }^{20}$

The results thus indicate that the perceived nasal obstruction is caused largely by other factors than a narrow nasal passage. The significant correlation between nasal symptoms (including obstruction) and mucociliary clearance in the woodwork teachers rather indicates that an impaired cleaning function of the nose plays an important part in the complaints. Impaired mucociliary clearance implies that wood dust particles and other airborne irritants deposited in the nasal mucosa remain there long enough to cause mucosal irritation. Most woodwork teachers had a reversible impairment of the mucociliary clearance, but two of them still had a pathological value after a weekend without exposure to wood dust. For exclusion of chronic effects, new tests should be performed after a longer break from exposure-for example, after the summer holidays.

Impaired sense of smell has been reported among other wood workers. ${ }^{21}$ The findings of a slightly impaired sense of smell at the end of a working week in the nine woodwork teachers reporting impaired smell, and the significant correlations between rated nasal symptoms, mucociliary clearance, and smell identification test results, indicate that the work related nasal mucosal symptoms and mucostas may cause a reversible impairment in sense of smell, a mechanism which has been discussed previously. ${ }^{622} 23$ On the other hand, the results from the present study do not indicate that work environment factors may cause chronic impairment of the sense of smell. This is in accordance with other studies where impairment of the sense of smell has been reported in groups exposed to airborne irritants but where improvement has been found after the end of exposure. ${ }^{24} 25$

EXPOSURE EFFECT RELATIONS

There were at most only weak correlations between the nasal complaints and observed and measured work environmental factors. Significant impairment of rated symptoms during the working week was most obvious in rooms without mechanical ventilation, indicating that air pollutants might be of importance for the complaints. There was no significant correlation between rated symptoms and tests and measured concentrations of total or respirable dust and terpenes, but in the woodwork teachers, changes in symptoms from Monday to Thursday correlated weakly with the percentage of respirable dust in the total dust. These facts give some support to the suspicion that the dust might be important in generating complaints, but the results are also somewhat contradictory because some symptoms correlated positively, others negatively. More studies are needed to evaluate the importance of different particle sizes in generating nasal complaints.

An impairment of mucociliary clearance has been reported in other studies of wood workers. $^{249}$ In a Danish study ${ }^{2}$ there was a dose effect relation between dust concentration and mucociliary clearance, but the dust concentrations were much higher than in the present study, where they were below the Swedish $\operatorname{TLV}\left(2 \mathrm{mg} / \mathrm{m}^{3}\right)$.

Other air pollutants may interact with wood dust to cause nasal complaints. The airborne terpene concentrations, which were very low ( $1 / 200$ of the TLV), were not related to the nasal complaints or the test results. The exposure to solvents, however, has not been measured. In the previous questionnaire study, ${ }^{8}$ use of solvents was related to respiratory symptoms. Most woodwork teachers used water based paints, lacquers, and glues intermittently, and such exposure may also cause mucosal irritation. ${ }^{26}$ However, woodwork with dust generation was predominant in the rooms, and therefore it seems reasonable to suspect wood dust as the main aetiological factor, although interaction with other pollutants cannot be excluded. The variation of exposure within and between working days has not been measured in this study, and this might be one explanation why so few dose effect relations were found. Also, exposure peaks shown by the direct reading instrument may be important, but the filter method does not measure such peaks.

We thank Annika Carlsson, Barbro Dölling, Birgit Ekdahl, Britt-Marie Inaeus, Marie-Louise Lind, Birgit Rousk, Anita Britt-Marie Inaeus, Marie-Louise Lind, Birgit Rousk, Anita Sundqvist, and Eva Thunberg for their aid in data collection.
The study was supported by the Swedish Work Environment Fund (91-0220).

1 Ruppe K. Diseases and functional disturbances of the respiratory tract in the woodworking industry. Zeitschrift fur die Gesamte Hygiene und ihre Grenzgebiete 1973;19:261-4.

2 Andersen HC, Andersen I, Solgaard J. Nasal cancers, symptoms and upper airway function in woodworkers. $B r$ f Ind Med 1977;34:201-7.

3 Werner U. Zur Einwirkung von Holzstäuben und Reizgasen auf den oberen Atemtrakt. Zeitschrift fur die Gesamte Hygiene und ihre Grenzgebiete 1979;25:290-3.

4 Wilhelmsson B, Drettner B. Nasal problems in wood furniture workers. Acta Otolaryngol 1984;98:548-55.

ture workers. Acta Otolaryngol 1984;98:548-55.
5 Holmström M, Wilhelmsson B. Respiratory symptoms and pathophysiological effects of occupational exposure to pathophysiological effects of occupational exposure to
formaldehyde and wood dust. Scand $₹$ Work Environ Health 1988;14:306-11. 
6 Holmström M, Rosén G, Wilhelmsson B. Symptoms, airway physiology and histology of workers exposed to medium-density fiber board. Scand $\mathcal{f}$ Work Environ Health 1991;17:409-13.

7 Pisaniello DL, Tkaczuk MN, Owen N. Occupational wood dust exposures, life style variables, and respiratory symptoms. F Occup Med 1992;34:788-92.

8 Åhman M, Söderman E, Cynkier I, Kolmodin-Hedman B. Work-related respiratory problems in industrial arts teachers. Int Arch Occup Environ Health 1995;67: $111-8$.

9 Black A, Evans JC, Hadfield EH, Macbeth RG, Morgan A, Walsh $M$. Impairment of nasal mucociliary clearance in Walsh $\mathrm{M}$. Impairment of nasal mucociliary clearance in woodworkers

10 Åhman M, van Hage-Hamsten M, Johansson SGO. IgEmediated allergy to wood dusts probably does not explain the high prevalence of respiratory symptom among Swedish woodwork teachers. Allergy 1995;50: 559-62.

11 Levin J-O. Principles and methods for the sampling and analysis of substances on the list of occupational exposure limits. Arbetsmiljöinstitutet, Sweden. Arbete och Hälsa 1994:11. (In Swedish with English summary.)

12 Kumlien J, Schiratzki H. Methodological aspects of rhinomanometry. Rhinology 1979;17:107-14.

13 Broms P. Rhinomanometry. III. Procedures and criteria for distinction between skeletal stenosis and mucosal distinction between skeletal stenosis

14 Doty RL, Shaman P, Dann M. Development of the University of Pennsylvania smell identification test: a standardized micro-encapsulated test of olfactory function. Physiol Behav 1984;32:489-502.

15 Swedish National Board of Occupational Safety and Health. Hygieniska gränsvärden. Arbetarskyddsstyrelsens författningssamling 1993:9. (In Swedish.)

16 Hounan RF, Williams J. Levels of airborne dust in furni- ture making factories in the High Wycombe area. $\mathrm{Br} \mathcal{F}$ Ind Med 1974;31:1-9.

17 Hinds WC. Basis for particle size-selective sampling for wood dust. In: Advances in air sampling (3rd edition). American Conference of Governmental Industrial Hygienists. Michigan: Lewis, 1990;5:53-63.

18 Jones AS, Willatt DJ, Durham M. Nasal airflow: resistance and sensation. F Laryngol Otol 1989;103:909-11.

19 Hadfield EH. A study of adenocarcinoma of the paranasal sinuses in woodworkers in the furniture industry. $A n n R$ Coll Surg Engl 1970;46:301-19.

20 Lund VJ, Holmström M, Scadding GK. Functional endoscopic sinus surgery in the management of chronic rhinosinuitis. An objective assessment. 7 Laryngol Otol 1991; 105:832-5.

21 Innocenti A, Valiani M, Vessio G, Tassini M, Gianelli T, Fusi S. Wood dust and nasal diseases: exposure to chestnut wood dust and loss of smell (pilot study). Med Lav 1985;76:317-20.

22 Estrem S, Renner G. Disorders of smell and taste. In: Holt GR, ed. Neurologic disorders in otolaryngology. Otolaryngol Clin North Am 1987;20:133-41.

23 A kerlund A, Bende M, Murphy C. Olfactory threshold and nasal mucosal changes in experimentally induced comnasal mucosal changes in experimentally induced com-
mon cold. Acta Otolaryngol (Stockh) 1995;115: 88-92.

24 Ahlström R, Berglund $B$, Berglund $U$, Lindvall $T$. Impaired odor perception in tank cleaners. Scand $\mathcal{F}$ Work Environ Health 1986;12:574-81

25 Schwartz BS, Doty RL, Monroe C, Frye R, Barker S. Olfactory function in chemical workers exposed to acrylate and methacrylate vapors. Am F Publ Health 1989 79:613-8.

26 Hansen MK, Larsen M, Cohr K-H. Waterborne paints. A review of their chemistry and toxicology and the results of determinations made during their use. Scand $f$ Work Environ Health 1987;13:473-85.

\section{Correspondence and editorials}

Occupational and Environmental Medicine welcomes correspondence relating to any of the material appearing in the journal. Results from preliminary or small scale studies may also be published in the correspondence column if this seems appropriate. Letters should be not more than 500 words in length and contain a minimum of references. Tables and figures should be kept to an absolute minimum. Letters are accepted on the understanding that they may be subject to editorial revision and shortening.

The journal also publishes editorials which are normally specially commissioned. The Editor welcomes suggestions regarding suitable topics; those wishing to submit an editorial, however, should do so only after discussion with the Editor. 